\title{
Discussion on the Online Fusion of Fresh Agricultural Products in the Internet age
}

\author{
YinfengLiu \\ Xi'anInternationalUniversity, $\mathrm{Xi}$ an,710077, China
}

\begin{abstract}
With the deepening development of the market economic system in our country, the marketization of fresh agricultural products is gradually accelerating. However, due to the seasonal characteristics of fresh produce, it is not appropriate for long-term preservation, and so on. In the Internet era, the rise of e-commerce has provided a new development path for the marketing of fresh agricultural products. Therefore, the online and offline integration of innovative agricultural products using the Internet has become a major trend in the development of commodity agriculture in China. This paper starts from the online and offline modes of fresh agricultural products, and explores the necessity of the online and offline integration of fresh agricultural products in the Internet age and the existing problems, and puts forward the corresponding fusion strategies for the problems.
\end{abstract}

Keywords: Internet; Fresh produce; Necessity; Measures

\section{Introduction}

Fresh agricultural products mainly refers to agricultural and sideline products which can not be stored for a long time under the normal temperature, such as fruits, vegetables, meat, aquatic products, eggs and so on, which have not been cleaned, trimmed, cut, graded and packaged. In recent years, with the development of economy, the market of fresh agricultural products has been expanding, and the types and quantity of agricultural products have been rising. However, due to the lag of market regulation and the particularity of vigorous agricultural products, it often appears in the marketing process. Seasonal, periodic and regional relative surplus situation, such as a few years ago in some 
areas of China have emerged citrus, tomatoes, potatoes, cabbage and other agricultural products, a large backlog of poor sales, leading to rapid decline in market prices situation. In order to break through this dilemma, we must make full use of the role of the Internet in the industrial transformation, optimize the marketing model of fresh agricultural products, use e-commerce to achieve online and offline integration of fresh agricultural products, so as to speed up the circulation of agricultural products, Production and sustainable development.

\section{Fresh agricultural products online and offline mode}

At present in China's unsullied agricultural products market, online marketing model mainly includes the following: First, the farmers market. This model is the most traditional line marketing model, but also urban and rural residents to buy fresh agricultural products, the main place in the farmers market, which not only includes fresh agricultural products sales links, including trafficking, leasing, preservation and other sectors, And because of the large number of participants in the farmers market, fresh agricultural products in the loss is relatively large, in addition to farmers market fresh agricultural products in the transport capacity and sales capacity mismatch often leads to commodity prices, thus affecting the supply of farmers Of the enthusiasm; Second, the agricultural and sideline products wholesale market. The mode of market radiation range, under normal circumstances is the main wholesale market from the production base or supplier procurement of fresh agricultural products, and then at wholesale prices to enterprises or individuals to provide goods, with the development of modern information technology, many of our country Agricultural products wholesale markets have achieved the procurement, storage, transportation, digital management; Third, large supermarkets. In the past, operators often use fresh agricultural products category to attract consumers, while ignoring the quality of goods, loss, profits, and in the government for agricultural super-docking reform , Many large supermarkets and farmers, cooperatives formed between the interests of the chain, thus greatly ensuring the quality of fresh agricultural products, but also reduces the marketing costs of the supermarket; Fourth, the fresh supermarket. And large supermarkets, supermarkets are exclusive products supermarkets, usually set up in the vicinity of the community, on the one hand they use market means and farmers, cooperatives to establish contact, on the other hand will use information means to complete a fresh market in a region Forecast, thus reducing the impact of market volatility on merchandise sales.

In the continuous development of e-commerce today, fresh agricultural products online marketing model is the following: First, the electricity commodity Taiwan. At present, some of the influential power of the business platform, such as the cat and so have launched a fresh agricultural marketing content, the sales platform to use its original brand, to provide consumers with high-quality fresh agricultural products at home and abroad, and improve the Consumer services; Second, the vertical electricity providers. The business model of the division of labor through the market, the management of fresh agricultural 
products will be meticulous management and use of modern information collection platform to understand the consumer's propensity to consume, combined with the source of procurement to achieve the quality of fresh agricultural products to ensure that consumption Online shopping attractive; Third, the integrated electricity providers. The model is the main manifestation of the expansion of e-commerce in the fresh agricultural market, that is, investment and $\mathrm{M} \& \mathrm{~A}$ is used in the field of freshness. Through the innovation of marketing mode, the centralized management of commodity sales can be realized to reduce the online marketing. Cost, improve the electricity business enterprises operating profit.

\section{The Internet era of fresh agricultural products online and offline integration of the need}

In the Internet, drove the development of e-commerce more mature, more and more extensive coverage of online sales, and the emergence of a common line of online and offline development. From the current development of China's market point of view, the realization of online and offline integration, whether for consumers or the development of wholesome market is very necessary. First of all, online and offline marketing model of the goal is the same. In China's fresh agricultural products line operators are mainly faced with high-end consumers, and line operators in almost all consumers, regardless of what type of consumer, its pursuit of safe and healthy goods is Will never change, but different consumers are willing to pay for the pursuit of different prices, in addition, for some offline consumers, such as the elderly, they are not only due to the impact of consumer habits, more More is because it will not be online shopping, so the realization of online and offline mode of integration is to expand the scope of our fresh market services to improve the effectiveness of fresh products marketing an important measure; Second, the use of cold chain logistics Making fresh agricultural products online and offline integration easier. Fresh agricultural products are perishable, perishable agricultural and sideline products, and in order to ensure transport safety, to extend its storage time, it must have the cold chain logistics intervention, China's online trading platform in order to ensure fresh agricultural product quality, Are used in refrigerated transport, and online mode, some large supermarkets, supermarket chains, etc. also used a fresh cold chain logistics to ensure the quality of transport, so that in the cold chain logistics driven, fresh agricultural products online and offline logistics model Integration, has become an important way to ensure the effectiveness of marketing.

\section{Fresh agricultural products on-line integration of the existing problems}

Although the promotion of the Internet and the support of national policy, China's 
fresh agricultural products online and offline integration has been launched, but there are still some problems cannot be ignored: First, the rural logistics development lag. In recent years, driven by e-commerce, the rapid development of logistics business, now in the city has almost established a centralized and perfect logistics network, which is for farmers around the city's agricultural transactions brought convenience, but in rural areas, As the supporting facilities are backward and the operating cost is too high, many logistics enterprises are reluctant to go deep into development, which causes some scattered farmers can not complete the distribution of agricultural products through the logistics system, thus losing the support of online and offline integration of agricultural products; Second, the transport sector of the disorderly competition. At present, in the circulation of fresh agricultural products, there are a large number of self-employed farmers, who are mostly farmers, have rich experience in the selection of pastoral products market and make great contributions to the circulation of agricultural products. However, Service awareness, lack of management and transportation preservation knowledge, resulting in disorderly competition in the market, and such a logistics environment will inevitably affect consumer online and offline evaluation of the quality of fresh agricultural products, thus limiting the online and offline marketing model Of the integration; Third, the flow of fresh agricultural products, the level of market-oriented low. In most rural areas of China, due to the lack of basic Internet coverage, farmers not only can not keep abreast of the fluctuation information of fresh agricultural products market, but also can not achieve online transactions, therefore, the lack of targeted market orientation, The market supply of blindness and hysteresis, thus limiting the effectiveness of online and offline marketing.

\section{To achieve the Internet era of fresh agricultural products online and offline integration measures}

In the initial stage of the online trading of fresh agricultural products, many electricity providers have achieved the expected business goals. However, due to the lack of development planning in the follow-up development, there have been some misunderstandings and resulted in the loss of clients. From this business experience, we should recognize that in the line of innovative agricultural production line integration process, good long-term development planning is very necessary. Operators in the process of developing the development plan on the one hand to step by step, to avoid the development of barbaric growth brought about by the drawbacks of the first through a particular kind of goods or a detailed plan to increase consumer loyalty, Under the integration of the basis; the other hand, we should attach importance to regional differences, grasp the preferences of consumers in different regions in order to achieve online and offline marketing personalized development.

In the process of on-line and off-line integration, customers have higher demands on the quality and variety of fresh agricultural products. Therefore, 
operators should focus on quality in products to provide consumers with richer categories, and more secure quality. Enterprises to achieve the goal of improving the quality of fresh produce production, on the one hand to in-depth rural and production base, and farmers, cooperatives to establish close contact and take appropriate measures to encourage farmers and cooperatives to standardize the cultivation, so that the source to ensure fresh produce Quality; on the other hand should also be strictly planned logistics system to avoid the loss of logistics process, thereby enhancing consumer satisfaction with the quality of fresh agricultural products.

Based on the status of agriculture in national economic construction, the government should make use of macroeconomic policies to improve the support of fresh agricultural products market, so as to speed up the integration of fresh agricultural products on the line and the line. The advance of fresh produce market is an important part of China's agricultural development. Pace. On the one hand, from the aspect of financial support, the government can help the electric business enterprises to complete the financing problem and provide material guarantee for their operation and sales. On the other hand, they should make use of capital, Technical support, to build a more comprehensive information technology platform to ensure that farmers, cooperatives, line the main marketing and online marketing platform to achieve positive communication between, in order to achieve the depth of online transactions and online retail integration.

Because of the particularity of fresh agricultural products, its loss in transportation not only reduces the quality of goods, but also increase the operating costs of enterprises, so enterprises in the process of online and offline integration, should pay attention to the cold chain logistics warehouse system Perfect, that is, to ensure that fresh agricultural products, refrigerated transport, so as to effectively reduce its loss in the transport process. In improving the cold chain logistics and warehousing system in the process, the enterprises on the one hand, according to the price of fresh agricultural products and transport distance to develop transport schedules to effectively control the transport costs; the other hand, should also set up cold storage logistics standards to ensure procurement, Processing, packaging, storage of all aspects of the safe and efficient.

A comprehensive quality tracking system not only allows online customers to shop with confidence, but also optimizes all aspects of online and offline transactions. Enterprises in the establishment of a sound quality of fresh agricultural products tracking system in the process of the first in accordance with the Government's food safety standards to determine the quality of fresh products; followed by bar code, two-dimensional code technology to achieve automatic identification of fresh agricultural products and data collection to ensure Resources, and finally relying on the Internet of things to control the production of fresh agricultural products, circulation, sales and other aspects of information to ensure that every commodity can use information products Taiwan to achieve the information back investigation, and then improve the level of online and offline integration. 


\section{Conclusion}

In summary, the Internet continues to develop today, relying on the advantages of the Internet to achieve the integration of fresh produce and agricultural line platform development, not only conducive to promoting the unified management of agricultural markets, logistics and distribution information can also be achieved visibility. Therefore, in the course of carrying out fresh market management, China should use the policy of "Internet + " to actively integrate the advantages of resources within the system to create a new network of fresh agricultural products with advantages of complementary, up and down, resource sharing and efficient operation Platform, so as to provide consumers with high-quality goods at the same time, but also to achieve the fresh and fresh agricultural products market, sustained and healthy development.

\section{Acknowledgements}

The research work was supported byShaanxi Provincial Department of Education special research project, project number 16JK2170,Topic: Internet + Shaanxi F2F model of fresh agricultural products and implementation of the program

\section{References}

[1] Zhang Yan. Internet era of fresh agricultural products online and offline integration [J]. Logistics Engineering and Management, 2015,07: 165-166.

[2] Li Ruiqiang. "Internet +" era of agricultural electronic business platform online and offline integration service model [J]. Agricultural Economics, 2016,11: 120-122.

[3] GE Ji-hong, ZHOU Shu-dong, WANG Wen-hao.The Marketing and Rebuilding of Agricultural Products in the Internet Era - Illustration from "Chu Orange" [J], Agricultural Economics, 2016, 10: 51-59+ 111 .

[4] Liu Huan. The plight and outlet of agricultural product circulation under the on-line and down-line development model [J]. Journal of Business Economics, 2016,18: 147-149. 